\title{
Avaliação ortopantomográfica das angulações mesiodistais de caninos, pré-molares e molares inferiores com e sem a presença dos terceiros molares
}

\author{
Rodrigo Castellazzi Sella*, Marcos Rogério de Mendonça**, Osmar Aparecido Cuoghi**
}

\section{Resumo}

Objetivos: comparar os valores médios normais das angulações mesiodistais dentárias, propostos por Ursi, em 1989, com as angulações mesiodistais de caninos, pré-molares e molares inferiores em indivíduos com e sem a presença dos terceiros molares inferiores e idades entre 18 e 25 anos. Além disso, foram comparados os valores das angulações mesiodistais desses dentes nessas duas situações. Métodos: foram utilizadas 40 radiografias ortopantomográficas de indivíduos, de ambos os gêneros, que não receberam tratamento ortodôntico, divididos em dois grupos: Grupo I, constituído por 20 radiografias que não apresentavam os terceiros molares inferiores; e Grupo II, formado por 20 radiografias com os terceiros molares inferiores presentes. Resultados e Conclusões: a análise dos resultados e a análise estatística permitiram concluir que ambos os grupos exibiram pré-molares e molares inferiores mais angulados em sentido mesial, quando comparados à oclusão normal. Por outro lado, a angulação mesiodistal de caninos inferiores mostrou-se semelhante àquela apresentada em casos de oclusão normal. Os dois grupos, quando comparados entre si, exibiram semelhantes valores angulares dos caninos, pré-molares e molares inferiores, de modo que a presença dos terceiros molares não exerceu influência sobre essas angulações mesiodistais dentárias.

Palavras-chave: Terceiro molar. Ortopantomografia. Angulações dentárias. Movimentação dentária.

\section{INTRODUÇÃO E REVISÃO DE LITERATURA}

Ao longo da história da Ortodontia, foram demonstradas diferentes formas de se obter a angulação correta dos dentes ao término do tratamento ortodôntico. Primeiro por meio de dobras artísticas nos fios, seguidas por braquetes soldados angulados nas bandas, de acordo com Holdaway ${ }^{13}$, e culminando na mais recente evolução para obtenção desse objetivo da Ortodontia: os braquetes totalmente ajustados desenvolvidos por Andrews ${ }^{2}$, que incorporam aos braquetes padrão os requisitos necessários para obtenção das "seis chaves para

* Mestre em Ortodontia pelo programa de pós-graduação em Odontologia da Faculdade de Odontologia de Araçatuba - Unesp. Doutorando em Ortodontia pelo programa de pós-graduação em Odontologia da Faculdade de Odontologia de Araçatuba - Unesp. Professor do departamento de Anatomia, área de Anatomia Humana, do Centro de Ciências Biológicas da Universidade Estadual de Londrina - UEL.

** Professor assistente doutor do departamento de Odontologia Infantil e Social, Disciplina de Ortodontia Preventiva, da Faculdade de Odontologia de Araçatuba - Unesp. 
a oclusão normal", dispensando, em grande parte dos casos, a maioria das dobras nos arcos.

A busca contínua pela angulação dentária adequada, no sentido mesiodistal, ocorreu em virtude do posicionamento dentário constituir um fator extremamente importante para que a estabilidade do sistema estomatognático possa ser mantida por meio da neutralização das forças oclusais em função normal ${ }^{21,22}$.

Nesse sentido, a componente anterior de forças está intimamente relacionada com pontos de contatos dentários bem definidos, dependentes de uma inclinação axial correta e do relacionamento da oclusão de um dente contra dois dentes. Assim, a inclinação axial adequada deve estar incluída nos objetivos do tratamento ortodôntico, pois está diretamente relacionada com o alinhamento dentário, além de tratar-se de um fator determinante para a manutenção em longo prazo dos resultados atingidos com o tratamento ${ }^{8,11}$.

A ortopantomografia, frequentemente denominada radiografia panorâmica, constitui um método auxiliar de diagnóstico que permite a visualização de uma série de estruturas anatômicas e fatores relevantes à Odontologia, de forma que o próprio nome sugere a visualização de um panorama geral do sistema estomatognático. A simplicidade de operação dos aparelhos e o grande número de informações obtidas, em conjunto com o conforto para o paciente e pequena quantidade de exposição à radiação, fazem da ortopantomografia um instrumento muito utilizado na Odontologia e em especial na Ortodontia, que desenvolveu métodos para utilizá-la na avaliação das angulações dentárias mesiodistais ${ }^{26,28}$.

Por outro lado, os terceiros molares vêm sendo um tema muito discutido no cenário odontológico. Robinson (1859, apud Southard ${ }^{23}$ ) afirmou que as irregularidades no posicionamento dos dentes são, frequentemente, o resultado da pressão exercida pelos terceiros molares. Desde então, esses dentes geraram muitas controvérsias, no contexto clínico-científico, quanto ao procedimento mais adequado diante de sua presença.

Existem duas linhas de raciocínio que concernem o desenvolvimento dos terceiros molares. A primeira, mais antiga, afirma que esses dentes são capazes de causar interferências, gerando certas irregularidades no posicionamento dos dentes adjacentes $3,15,16,29$. Contudo, a segunda linha apregoa que os terceiros molares não apresentariam essa capacidade de proporcionar tantos efeitos deleté$\operatorname{rios}^{1,14,18,19,20,23,24,30}$.

Apesar do grande número de publicações direcionadas à abordagem desse tema, muitas são as incertezas em relação à conduta correta frente às inúmeras situações e se a presença desses dentes é capaz de causar alterações no posicionamento dos demais. Dentro desse contexto, existe uma escassez de trabalhos que relacionam a possível variação que a presença ou ausência dos terceiros molares podem causar nas angulações mesiodistais dos dentes adjacentes, o que motivou a elaboração da presente pesquisa.

\section{Terceiros molares}

Na revisão da literatura referente à presença, ao desenvolvimento e à influência dos terceiros molares constata-se inúmeras controvérsias, em virtude da existência de duas linhas de raciocínio distintas concernentes ao desenvolvimento desses dentes.

Em 1989, Richardson ${ }^{20}$ inferiu que a pressão exercida na região posterior e a presença do terceiro molar podem constituir as causas do apinhamento tardio no arco inferior, mas explicou que existem outros fatores etiológicos envolvidos. Cinco anos depois, a mesma autora explicou que o crescimento mandibular tardio, a maturação dos tecidos moles, as forças periodontais e as estruturas dentárias e esqueléticas, bem como os fatores oclusais e o padrão de crescimento, são a essência multifatorial para a alteração do posicionamento dos dentes inferiores ${ }^{19}$.

O predomínio da ideia da influência dos terceiros molares nos dentes adjacentes foi eviden- 
ciado no estudo de Laskin $^{15}$, que, por meio de uma pesquisa com mais de 600 ortodontistas e 700 cirurgiões-dentistas, concluiu que $65 \%$ dos profissionais compartilhavam da opinião de que os terceiros molares podem produzir apinhamento anteroinferior.

\section{Angulação axial mesiodistal}

Os objetivos do tratamento ortodôntico dependem de alguns fatores e, dentre eles, encontra-se a angulação dentária mesiodistal correta, destacada por Andrews em seu artigo clássico ${ }^{2}$ publicado em 1972. Os longos eixos dentários, quando posicionados corretamente, fornecem condições adequadas para que o equilíbrio oclusal seja atingido e estabelece-se como um importante requisito para a obtenção da estabilidade dos resultados gerados pelo tratamento ${ }^{9,12}$.

Dessa forma, a busca pela angulação dentária mesiodistal semelhante à da oclusão normal deve-se ao fato dessa oclusão apresentar harmonia entre os componentes do sistema estomatognáti$\mathrm{CO}^{28}$. Nesses casos, os longos eixos dentários apresentam-se, de acordo com sua localização no arco, angulados com as raízes para distal em níveis variados $^{2}$. O espaço para cada dente varia conforme essas angulações, que geram contatos proximais justos, além de um relacionamento adequado no sentido anteroposterior ${ }^{2}$.

A pesquisa de 1989 de $\mathrm{Ursi}^{28}$ avaliou uma amostra constituída por 42 jovens brasileiros leucodermas com oclusão "normal", com idades entre 12 e 17 anos. Destacou-se a radiografia panorâmica como um método confiável para a tomada de medidas angulares e estabeleceu-se um padrão para as angulações axiais mesiodistais.

Por outro lado, considerando a dinâmica do sistema estomatognático, as forças oclusais devem ser direcionadas para o longo eixo dos dentes ${ }^{25}$. Uma parcela dessas forças é eliminada por meio do componente anterior, estabelecido a partir dos dentes posteriores ${ }^{8,11}$. Sua completa neutralização ocorre exatamente na linha média, pela força proveniente do hemiarco do lado oposto ${ }^{11}$. Assim, uma adequada dissipação das forças oclusais depende das angulações dentárias e planos inclinados das faces oclusais ${ }^{8,11,21}$.

Quando as angulações mesiodistais encontramse inadequadas, a possibilidade de ocorrência de reabertura de espaços fechados por meio do tratamento ortodôntico aumenta, em decorrência do paralelismo radicular incorreto ${ }^{9,12,13,25}$. O aumento dessas angulações pode, ainda, compensar certas discrepâncias de tamanho dentário interarcos e otimizar a estabilidade do alinhamento dentário na região anteroinferior ${ }^{27}$.

Quanto à estabilidade do posicionamento dentário obtido por meio do tratamento ortodôntico e ocorrência de recidiva, Ferrario et al. ${ }^{10}$ explicaram que a alteração da angulação dentária relacionada com a idade pode ser o efeito de um deslocamento mesial progressivo.

A busca para obtenção clínica da angulação axial mesiodistal correta envolveu desde alterações no posicionamento dos braquetes ${ }^{13,22}$ até a sua incorporação nos acessórios ${ }^{5,22}$. Pesquisas que compararam a efetividade de técnicas ${ }^{4}$, investigações concernentes ao posicionamento mesiodistal dos incisivos permanentes superiores na fase de dentadura mista ${ }^{6}$ e estudos que avaliaram a obtenção das angulações axiais corretas comparando-as ao início e ao término do tratamento ${ }^{17}$ reiteram a importância do assunto.

Contudo, esse importante fator envolvido com a estabilidade oclusal mostra-se pouco discutido quanto à possibilidade de alterações relacionadas com a presença dos terceiros molares, fato que motivou o desenvolvimento do presente trabalho.

\section{PROPOSIÇÃO}

O propósito dessa pesquisa consiste em comparar os valores médios normais das angulações mesiodistais dentárias propostos por $\mathrm{Ursi}^{28} \mathrm{com}$ as angulações mesiodistais de caninos, pré-molares e molares inferiores em indivíduos com e sem a presença dos terceiros molares inferiores e, ainda, 
comparar os valores das angulações mesiodistais de caninos, pré-molares e molares inferiores nessas duas situações.

\section{MATERIAL E MÉTODOS}

Para esse estudo prospectivo, a amostra constou de 40 radiografias ortopantomográficas de indivíduos adultos brasileiros de ambos os gêneros, entre 18 e 25 anos de idade, que não haviam recebido tratamento ortodôntico e apresentavam todos os dentes, com exceção dos terceiros molares, que estavam ausentes em metade da amostra devido à agenesia. Dessa forma, as radiografias foram distribuídas em dois grupos, sendo o Grupo I constituído por 20 radiografias com ausência dos terceiros molares inferiores devido à agenesia, enquanto o Grupo II foi formado a partir de 20 radiografias com os terceiros molares inferiores presentes. As figuras 1 e 2 exibem radiografias panorâmicas de integrantes do Grupo I e do Grupo II, respectivamente, e permitem a visualização das duas condições analisadas.

Cabe salientar que todos os integrantes da amostra apresentavam má oclusão, sendo que, no Grupo I, 12 exibiam má oclusão de Classe I (6 femininos e 6 masculinos) e 8 apresentavam má oclusão de Classe II ( 5 femininos e 3 masculinos).

Considerando os cinco indivíduos portadores de má oclusão de Classe II do gênero feminino, três exibiam má oclusão de Classe II divisão 1 e dois apresentavam má oclusão de Classe II divisão 2. Por outro lado, os três indivíduos portadores de

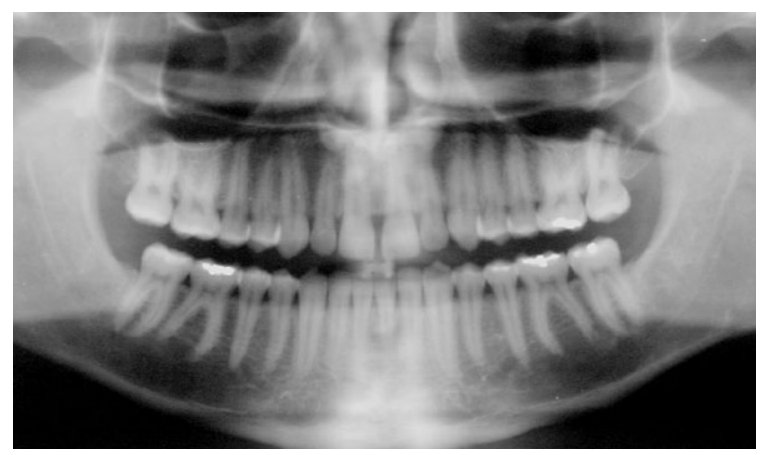

FIGURA 1 - Radiografia ortopantomográfica incluída no Grupo I (sem a presença dos terceiros molares inferiores). má oclusão de Classe II do gênero masculino exibiam má oclusão de Classe II divisão 1 .

Já no Grupo II, metade da amostra apresentou má oclusão de Classe I (6 femininos e 4 masculinos) e a outra metade exibiu má oclusão de Classe II (4 femininos e 6 masculinos).

Considerando os quatro indivíduos portadores de má oclusão de Classe II do gênero feminino, dois exibiam má oclusão de Classe II divisão 1 e dois apresentavam má oclusão de Classe II divisão 2. Por outro lado, dos seis indivíduos portadores de má oclusão de Classe II do gênero masculino, quatro exibiam má oclusão de Classe II divisão 1 e apenas dois apresentavam má oclusão de Classe II divisão 2.

Todas as radiografias foram obtidas em um mesmo aparelho (Rotograph Plus ${ }^{\circledR}$, Del Medical Imaging Corp., EUA) e por um único operador.

Para elaborar o traçado de orientação, utilizouse: negatoscópio, moldura de cartolina preta, papel de acetato transparente Ultraphan ${ }^{\circledR}$ de $21,0 \mathrm{~cm}$ de comprimento por $14,5 \mathrm{~cm}$ de largura e espessura de $0,07 \mathrm{~mm}$, fita adesiva transparente, lapiseira com grafite $0,5 \mathrm{~mm}$, borracha branca macia e régua milimetrada.

Durante a seleção das radiografias do Grupo II, estabeleceu-se que os terceiros molares deveriam apresentar o desenvolvimento radicular no mínimo no estágio $\mathrm{F}$ de desenvolvimento, de acordo com Demirjian et al. ${ }^{7}$ (comprimento radicular igual ao comprimento coronário, proporção 1:1).

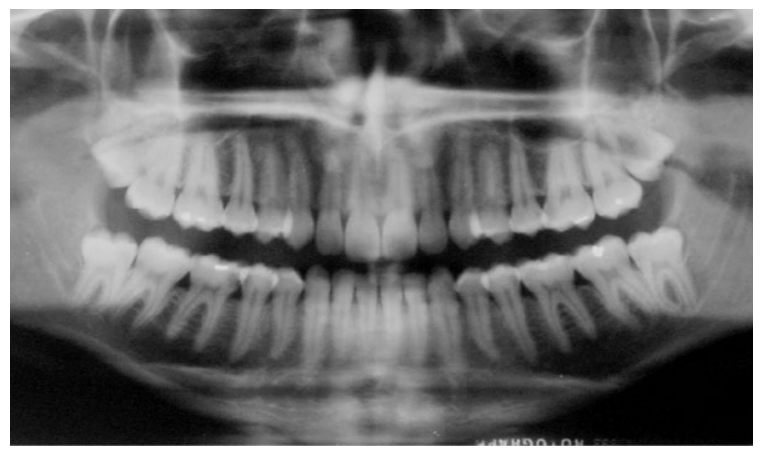

FIGURA 2 - Radiografia ortopantomográfica incluída no Grupo II (com a presença dos terceiros molares inferiores). 
Esse estágio foi eleito em virtude do dente apresentar grande parte de seu desenvolvimento radicular e alto potencial de irrupção, além da possibilidade de quantificação e padronização da amostra do Grupo II.

Para determinar a proporção mínima de 1:1 entre os comprimentos radicular e coronário, inicialmente traçou-se uma linha na região oclusal dos terceiros molares inferiores unindo as cúspides mesial e distal. Em seguida, foram estabelecidos os limites mesial e distal, perpendiculares ao plano oclusal e o longo eixo dentário, também perpendicular ao plano oclusal, passando pelo ponto médio da distância mesiodistal. Conforme a definição do estágio $\mathrm{D}$ de desenvolvimento de Demirjian et. al. ${ }^{7}$, a coroa atinge sua formação completa ao evidenciar-se o limite amelocementário. Desse modo, a determinação do limite amelocementário e do limite radicular, paralelos ao plano oclusal, permitiu a mensuração dos comprimentos coronário e radicular sobre o longo eixo dentário (Fig. 3).

Os comprimentos coronário e radicular foram medidos diretamente nas radiografias, por meio de um paquímetro digital (Digimatic Caliper ${ }^{\circledR}$ ) da marca Mitutoyo Sul Americana Ltda, com certificado de aferição 500-143B.
Sobre cada radiografia, foi adaptada uma folha de papel de acetato Ultraphan ${ }^{\circledR}$ com $21,0 \mathrm{~cm}$ de comprimento por $14,5 \mathrm{~cm}$ de largura e espessura de $0,07 \mathrm{~mm}$. As estruturas dentoesqueléticas traçadas sobre as radiografias, conforme Tavano et $\mathrm{al}^{2}{ }^{26}$, foram: contorno externo da imagem da mandíbula, forames mentonianos, contorno externo de caninos, pré-molares e molares inferiores. Posteriormente, foram demarcados os pontos Forame Mentoniano Direito $\left(\mathrm{FM}_{\mathrm{d}}\right)$ e Forame Mentoniano Esquerdo $\left(\mathrm{FM}_{\mathrm{e}}\right)$, que são os pontos mais centrais dos forames mentonianos.

A linha intermentoniana (IM) foi a linha de referência utilizada para a realização das medições angulares dos dentes inferiores nas radiografias ortopantomográficas que, segundo Tavano et al. ${ }^{26}$, deve passar pelo centro dos forames mentonianos (Fig. 4).

Para determinação dos longos eixos dos dentes unirradiculares (caninos, primeiros e segundos pré-molares) foi utilizada a imagem do canal radicular em sua maior extensão, enquanto os longos eixos dos dentes birradiculares (primeiros e segundos molares) seguiram a média das imagens dos canais radiculares, de acordo com Ursi ${ }^{28}$ (Fig. 4, 5).

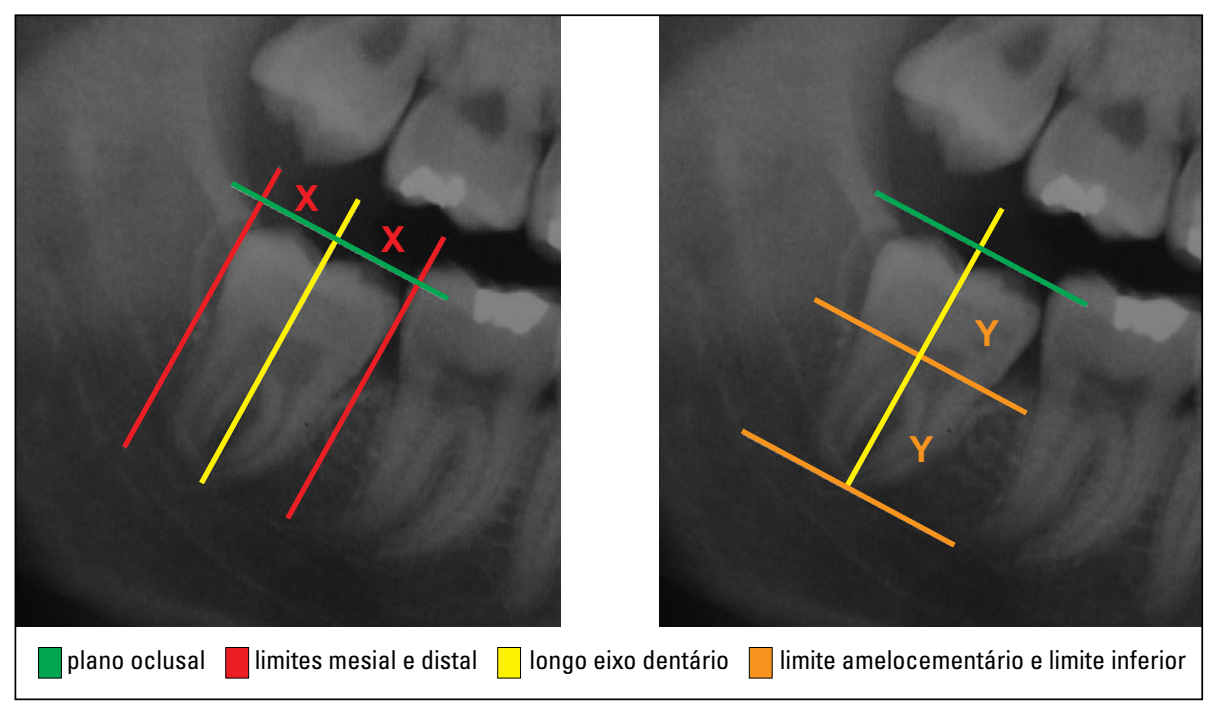

FIGURA 3 - Metodologia utilizada para seleção das radiografias com a presença dos terceiros molares inferiores (Grupo II). 


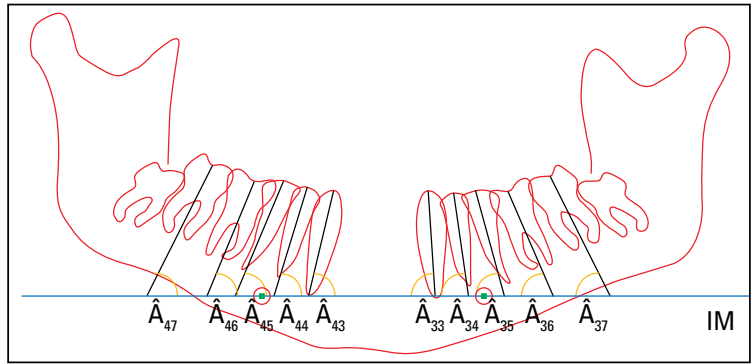

FIGURA 4 - Traçado de orientação com demarcação dos pontos $\mathrm{FM}_{d} \mathrm{e}$ $\mathrm{FM}_{\mathrm{e}^{\prime}}$, bem como da linha intermentoniana (IM) e dos longos eixos dentários do Grupo II (com a presença dos terceiros molares inferiores).

A intersecção dos longos eixos dentários com a linha de referência intermentoniana permitiu a obtenção dos seguintes ângulos (Fig. 4):

- $\hat{\mathrm{A}}_{33}$ e $\hat{\mathrm{A}}_{43}$ - ângulo formado pela intersecção da linha do longo eixo dos caninos inferiores, esquerdo e direito, respectivamente, com a linha intermentoniana.

- $\hat{\mathrm{A}}_{34}$ e $\hat{\mathrm{A}}_{44}$ - ângulo formado pela intersecção da linha do longo eixo dos primeiros pré-molares inferiores, esquerdo e direito, respectivamente, com a linha intermentoniana.

- $\hat{\mathrm{A}}_{35}$ e $\hat{\mathrm{A}}_{45}$ - ângulo formado pela intersecção da linha do longo eixo dos segundos pré-molares inferiores, esquerdo e direito, respectivamente, com a linha intermentoniana.

- $\hat{\mathrm{A}}_{36}$ e $\hat{\mathrm{A}}_{46}$ - ângulo formado pela intersecção da linha do longo eixo dos primeiros molares inferiores, esquerdo e direito, respectivamente, com a linha intermentoniana.

- $\hat{\mathrm{A}}_{37}$ e $\hat{\mathrm{A}}_{47}$ - ângulo formado pela intersecção da linha do longo eixo dos segundos molares inferiores, esquerdo e direito, respectivamente, com a linha intermentoniana.

Os traçados foram efetuados pelo pesquisador e conferidos por outros dois profissionais. Em seguida, foram digitalizados por meio de um scanner e os ângulos $\hat{\mathrm{A}}_{43}, \hat{\mathrm{A}}_{33}, \hat{\mathrm{A}}_{44}, \hat{\mathrm{A}}_{34}, \hat{\mathrm{A}}_{45}, \hat{\mathrm{A}}_{35}, \hat{\mathrm{A}}_{46}$, $\hat{\mathrm{A}}_{36}, \hat{\mathrm{A}}_{47}$ e $\hat{\mathrm{A}}_{37}$, formados pela intersecção dos longos eixos dos dentes com a linha intermentoniana, foram determinados pelo programa AutoCAD ${ }^{\circledR}$.

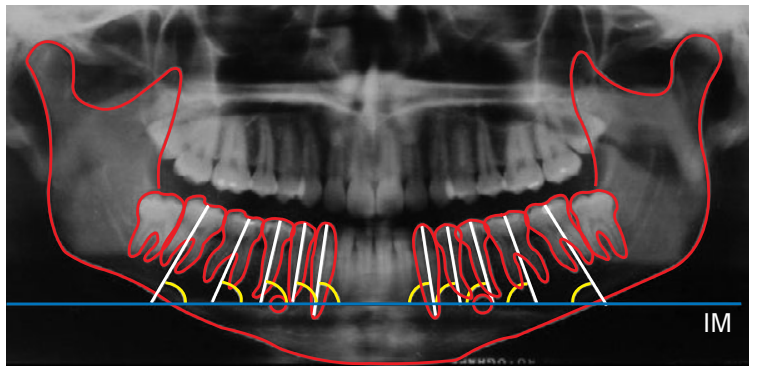

FIGURA 5 - Radiografia panorâmica do Grupo II (com a presença dos terceiros molares inferiores) com traçado que delimita suas estruturas dentoesqueléticas, pontos $\mathrm{FM}_{d}$ e $\mathrm{FM}_{\mathrm{e}^{\prime}}$ linha intermentoniana (IM), longos eixos dentários e ângulos formados pela intersecção dos longos eixos dos dentes com a linha intermentoniana.

\section{Análise estatística}

As médias foram comparadas entre os grupos de modo independente, ou seja, Grupo I x Grupo Controle, Grupo II x Grupo Controle e Grupo I x Grupo II. Para essa comparação, utilizou-se o teste t de Student em nível de 5\%.

\section{Erro do método}

O erro metodológico foi verificado por meio da seleção aleatória de dez radiografias panorâmicas do Grupo I e dez radiografias panorâmicas do Grupo II, que foram traçadas e medidas por duas vezes, pelo mesmo operador, em períodos diferentes. Por meio dessa repetição, obteve-se o erro casual e o erro sistemático.

Determinou-se o erro casual pela fórmula de Dahlberg: $\mathrm{Se}^{2}=\sum \mathrm{d}^{2} / 2 \mathrm{n}$, enquanto, para o erro sistemático, utilizou-se o teste $t$ de Student.

\section{RESULTADOS}

Previamente aos resultados específicos da pesquisa, as tabelas 1 e 2 demonstram os dados para estabelecer a possibilidade de erro do método.

Considerando as investigações destacadas por Pedrin et al. ${ }^{17}$, os valores do índice de Dahlberg foram reconhecidos como significativos quando acima de $1,5^{\circ}$.

A análise das tabelas 1 e 2 permite afirmar que os resultados obtidos por meio do método utilizado se apresentam dentro dos parâmetros 
TABELA 1 - Médias e desvios-padrão das diferenças, valores de t (erro sistemático), níveis de probabilidade de significância $(P)$ e índices de Dahlberg (erro casual) obtidos no Grupo I (sem os terceiros molares).

\begin{tabular}{cccccc} 
DENTE & MÉDIA & d.p. & $\mathbf{t}$ & $\mathbf{P}$ & DAHLBERG \\
\hline 47 & 0,87 & 0,48 & $-4,02$ & 0,99 & 0,98 \\
\hline 46 & 1,05 & 0,59 & $-2,34$ & 0,98 & 1,43 \\
\hline 45 & 0,88 & 0,76 & $-2,53$ & 0,98 & 1,31 \\
\hline 44 & 1,13 & 0,39 & $-2,93$ & 0,99 & 1,42 \\
\hline 43 & 0,92 & 0,47 & $-3,83$ & 0,99 & 1,05 \\
\hline 33 & 1,03 & 0,55 & $-2,64$ & 0,99 & 1,34 \\
\hline 34 & 1,06 & 0,49 & $-2,75$ & 0,99 & 1,36 \\
\hline 35 & 1,03 & 0,60 & $-2,45$ & 0,98 & 1,39 \\
36 & 1,05 & 0,56 & $-2,52$ & 0,98 & 1,38 \\
\hline 37 & 0,95 & 0,34 & $-5,03$ & 0,99 & 1,01 \\
\hline
\end{tabular}

TABELA 3 - Médias e desvios-padrão das angulações mesiodistais de caninos, pré-molares e molares inferiores do Grupo I (sem os terceiros molares).

\begin{tabular}{cccc} 
DENTE & $\begin{array}{c}\text { PANORÂMICAS } \\
(\mathrm{n})\end{array}$ & MÉDIA & d.p. \\
\hline 47 & 20 & 58,72 & 5,15 \\
46 & 20 & 65,36 & 5,50 \\
45 & 20 & 75,73 & 4,11 \\
44 & 20 & 82,14 & 4,65 \\
43 & 20 & 87,96 & 5,69 \\
33 & 20 & 84,60 & 5,77 \\
34 & 20 & 82,28 & 4,19 \\
35 & 20 & 73,58 & 4,26 \\
36 & 20 & 67,24 & 4,93 \\
37 & 20 & 60,93 & 5,70
\end{tabular}

aceitáveis, não comprometendo a fidelidade das conclusões da presente pesquisa.

As tabelas 3 e 4 ilustram os valores médios e desvios-padrão obtidos para caninos, pré-molares e molares nos Grupos I e II, respectivamente, enquanto a tabela 5 apresenta as médias dos Grupos I, II e Grupo Controle.

Já as tabelas 6 e 7 exibem os valores médios normais de cada dente, extraídos do trabalho de
TABELA 2 - Médias e desvios-padrão das diferenças, valores de t (erro sistemático), níveis de probabilidade de significância ( $P$ ) e índices de Dahlberg (erro casual) obtidos no Grupo II (com os terceiros molares).

\begin{tabular}{cccccc} 
DENTE & MÉDIA & d.p. & $\mathbf{t}$ & $\mathbf{P}$ & DAHLBERG \\
\hline 47 & 0,95 & 0,34 & $-5,03$ & 0,99 & 1,01 \\
46 & 0,93 & 0,62 & $-2,84$ & 0,99 & 1,23 \\
45 & 1,05 & 0,56 & $-2,52$ & 0,98 & 1,38 \\
44 & 1,06 & 0,49 & $-2,75$ & 0,99 & 1,36 \\
43 & 1,05 & 0,59 & $-2,34$ & 0,98 & 1,43 \\
33 & 1,13 & 0,39 & $-2,93$ & 0,99 & 1,42 \\
34 & 0,88 & 0,76 & $-2,53$ & 0,98 & 1,31 \\
35 & 1,03 & 0,60 & $-2,45$ & 0,98 & 1,39 \\
36 & 0,92 & 0,47 & $-3,83$ & 0,99 & 1,05 \\
37 & 0,87 & 0,48 & $-4,02$ & 0,99 & 0,98 \\
\hline
\end{tabular}

TABELA 4 - Médias e desvios-padrão das angulações mesiodistais de caninos, pré-molares e molares inferiores do Grupo II (com os terceiros molares).

\begin{tabular}{cccc} 
DENTE & $\begin{array}{c}\text { PANORÂMICAS } \\
(\mathbf{n})\end{array}$ & MÉDIA & d.p. \\
\hline 47 & 20 & 61,63 & 7,45 \\
\hline 46 & 20 & 68,06 & 6,09 \\
45 & 20 & 73,89 & 5,33 \\
44 & 20 & 81,67 & 3,49 \\
43 & 20 & 85,76 & 3,44 \\
33 & 20 & 84,84 & 5,70 \\
34 & 20 & 82,14 & 4,66 \\
35 & 20 & 73,49 & 5,85 \\
36 & 20 & 68,97 & 6,61 \\
37 & 20 & 62,79 & 7,93 \\
\hline
\end{tabular}

$\mathrm{Ursi}^{28}$ e utilizados nessa pesquisa como valores do Grupo Controle, bem como as médias dos valores obtidos nos Grupos I e II, respectivamente, e os níveis de probabilidade e significância.

Por fim, a tabela 8 apresenta as médias dos valores angulares de cada dente e a comparação dos valores obtidos para os Grupos I e II, bem como os valores de $\mathrm{P}$ com nível de probabilidade de significância estatística em 5\%. 
TABELA 5 - Valores médios das angulações mesiodistais de caninos, pré-molares e molares inferiores dos Grupos I, II e Controle.

\begin{tabular}{|cccc}
\hline DENTE & $\begin{array}{c}\text { MÉDIA } \\
\text { GRUPO I }\end{array}$ & $\begin{array}{c}\text { MÉDIA } \\
\text { GRUPO II }\end{array}$ & $\begin{array}{c}\text { MÉDIA } \\
\text { GRUPO CONTROLE }\end{array}$ \\
\hline 47 & 58,72 & 61,63 & 74,92 \\
46 & 65,36 & 68,06 & 82,64 \\
45 & 75,73 & 73,89 & 88,47 \\
44 & 82,14 & 81,67 & 86,42 \\
43 & 87,96 & 85,76 & 88,02 \\
\hline 33 & 84,60 & 84,84 & 86,11 \\
34 & 82,28 & 82,14 & 85,57 \\
35 & 73,58 & 73,49 & 88,69 \\
36 & 67,24 & 68,97 & 85,50 \\
37 & 60,93 & 62,79 & 76,92 \\
\hline
\end{tabular}

TABELA 7 - Valores médios normais (Grupo Controle) das angulações mesiodistais de cada dente individualmente, médias dos valores obtidos no Grupo II (com os terceiros molares) e níveis de probabilidade e significância.

\begin{tabular}{cccc} 
DENTE & $\begin{array}{c}\text { MÉDIA } \\
\text { GRUPO CONTROLE }\end{array}$ & $\begin{array}{c}\text { MÉDIA } \\
\text { GRUPO II }\end{array}$ & $P$ \\
\hline 47 & 74,92 & 61,63 & $0,0001^{*}$ \\
46 & 82,64 & 68,06 & $0,0001^{*}$ \\
45 & 88,47 & 73,89 & $0,0001^{*}$ \\
44 & 86,42 & 81,67 & $0,0001^{*}$ \\
43 & 88,02 & 85,76 & 0,02 \\
33 & 86,11 & 84,84 & 0,32 \\
34 & 85,57 & 82,14 & $0,0001^{*}$ \\
35 & 88,69 & 73,49 & $0,0001^{*}$ \\
36 & 85,50 & 68,97 & $0,0001^{*}$ \\
37 & 76,92 & 62,79 & $0,0001^{*}$ \\
\hline
\end{tabular}

*Diferenças estatisticamente significativas para $\mathrm{P}<0,05$.

\section{DISCUSSÃO}

A presente pesquisa preocupou-se em avaliar não somente o posicionamento angular dos primeiros e segundos molares, pré-molares e caninos, mas também em ampliar os conhecimentos a respeito da oclusão, independentemente da realização do tratamento.
TABELA 6 - Valores médios normais (Grupo Controle) das angulações mesiodistais de cada dente individualmente, médias dos valores obtidos no Grupo I (sem os terceiros molares) e níveis de probabilidade significância.

\begin{tabular}{cccc} 
DENTE & $\begin{array}{c}\text { MÉDIA } \\
\text { GRUPO CONTROLE }\end{array}$ & $\begin{array}{c}\text { MÉDIA } \\
\text { GRUPO I }\end{array}$ & $P$ \\
\hline 47 & 74,92 & 58,72 & $0,0001^{*}$ \\
46 & 82,64 & 65,36 & $0,0001^{*}$ \\
45 & 88,47 & 75,73 & $0,0001^{*}$ \\
\hline 44 & 86,42 & 82,14 & $0,0001^{*}$ \\
43 & 88,02 & 87,96 & 0,95 \\
\hline 33 & 86,11 & 84,60 & 0,25 \\
34 & 85,57 & 82,28 & $0,0001^{*}$ \\
35 & 88,69 & 73,58 & $0,0001^{*}$ \\
36 & 85,50 & 67,24 & $0,0001^{*}$ \\
37 & 76,92 & 60,93 & $0,0001^{*}$
\end{tabular}

*Diferenças estatisticamente significativas para $\mathrm{P}<0,05$.

TABELA 8 - Médias dos valores obtidos no Grupo I (sem os terceiros molares), médias dos valores obtidos no Grupo II (com os terceiros molares) e níveis de probabilidade de significância.

\begin{tabular}{cccc} 
DENTE & $\begin{array}{c}\text { MÉDIA } \\
\text { GRUPO I }\end{array}$ & $\begin{array}{c}\text { MÉDIA } \\
\text { GRUPO II }\end{array}$ & $\mathbf{P}$ \\
\hline 47 & 58,72 & 61,63 & 0,15 \\
46 & 65,36 & 68,06 & 0,14 \\
45 & 75,73 & 73,89 & 0,22 \\
\hline 44 & 82,14 & 81,67 & 0,89 \\
43 & 87,96 & 85,76 & 0,14 \\
33 & 84,60 & 84,84 & 0,89 \\
34 & 82,28 & 82,14 & 0,92 \\
35 & 73,58 & 73,49 & 0,95 \\
36 & 67,24 & 68,97 & 0,35 \\
37 & 60,93 & 62,79 & 0,40 \\
\hline
\end{tabular}

*Diferenças estatisticamente significativas para $\mathrm{P}<0,05$.

Os terceiros molares parecem exercer influência sobre o desenvolvimento dos arcos dentários, fato que não justifica a remoção do germe dentário ou exodontia desse dente, a não ser em circunstâncias excepcionais ${ }^{3}$.

A possível capacidade dos terceiros molares causarem alterações aos demais dentes e a dúvida 
diante de diferentes angulações dentárias envolvendo indivíduos com e sem a presença dos terceiros molares motivou a elaboração da presente investigação.

Primeiramente, foram comparados os valores obtidos individualmente nos Grupos I e II com os valores médios normais obtidos por $\mathrm{Ursi}^{28}$, compreendidos no Grupo Controle.

Cabe salientar que, de acordo com a metodologia empregada, valores angulares menores do que aqueles mostrados pelo Grupo Controle representam uma situação de angulação de coroa acentuada no sentido mesial.

Os resultados da comparação entre os valores angulares do Grupo I e do Grupo Controle demonstraram que ocorreu uma diferença estatisticamente significativa em nível de 5\% para prémolares e molares (Gráf. 1).

Deve ser salientado que os ângulos obtidos no Grupo I foram menores, para todos os dentes, quando comparados com o Grupo Controle. Esse fato estabelece que nas más oclusões de Classe I e Classe II que não exibem os terceiros molares, os dentes pré-molares e molares apresentam-se com suas coroas significativamente mais anguladas em sentido mesial em relação à oclusão normal.

De forma semelhante, os valores angulares referentes ao Grupo II, quando comparados com o Grupo Controle, exibiram diferença estatisticamente significativa em nível de 5\% para pré-molares e molares (Gráf. 2).

A mesma consideração concernente ao Grupo

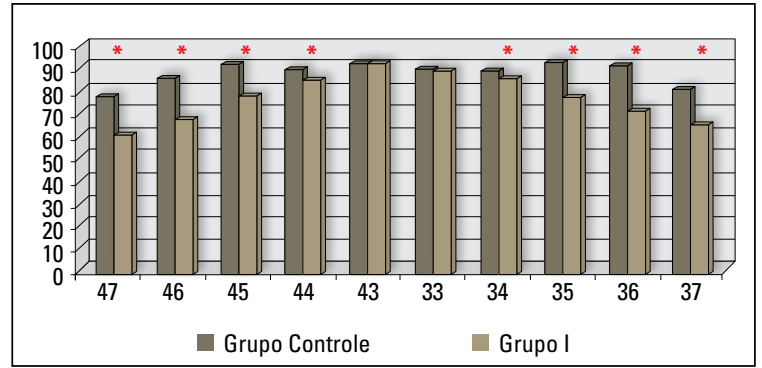

GRÁFICO 1 - Valores médios das angulações mesiodistais nos Grupos Controle e I.

* Diferenças estatisticamente significativas para $\mathrm{P}<0,05$.
I deve ser estabelecida para o Grupo II, uma vez que os ângulos obtidos para todos os dentes foram menores do que aqueles exibidos pelo Grupo Controle. Assim, pode-se inferir que, nas más oclusões de Classe I e Classe II que exibem os terceiros molares, os dentes pré-molares e molares apresentam-se com suas coroas mais anguladas em sentido mesial em relação à oclusão normal.

Considerando que casos tratados ortodonticamente devem apresentar, como meta ao término do tratamento, a mesma angulação mesiodistal apresentada na oclusão normal ${ }^{28}$, pode-se inferir que as angulações axiais mesiodistais de pré-molares e molares inferiores devem receber atenção especial ao término do tratamento, pois, conforme os resultados dessa pesquisa, os valores angulares presentes nas más oclusões mostraram-se menores em relação à oclusão normal.

Isso demonstra que, em grande parte dos tratamentos ortodônticos, os dentes posteriores, ou seja, pré-molares e molares, necessitam de um posicionamento mais verticalizado. No entanto, a verticalização do segmento posterior pode proporcionar um aumento da dimensão vertical, necessitando, dessa forma, uma avaliação mais complexa dos efeitos que essa verticalização pode provocar no padrão facial individual.

Essa situação fica evidente quando se observa o gráfico 1 (Grupo I) e o gráfico 2 (Grupo II).

Por outro lado, quando se comparou as médias das angulações mesiodistais de caninos, pré-molares e molares inferiores na presença (Grupo I) e na

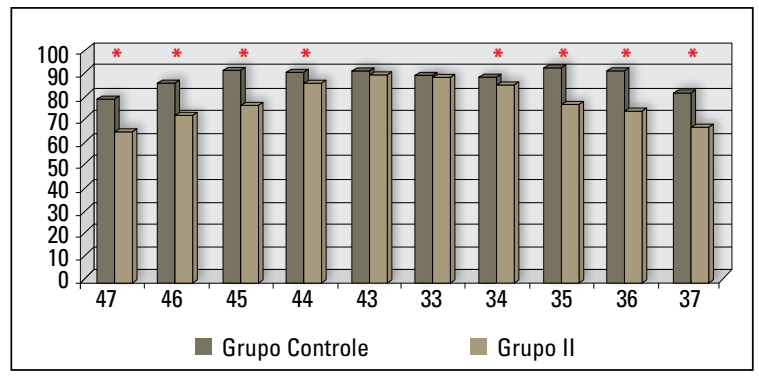

GRÁFICO 2 - Valores médios das angulações mesiodistais nos Grupos Controle e II.

* Diferenças estatisticamente significativas para $P<0,05$. 
ausência (Grupo II) dos terceiros molares inferiores (Gráf. 3), evidenciou-se a inexistência de diferença estatisticamente significativa entre os grupos.

Assim, considerando os resultados encontrados e a análise estatística realizada, pode-se observar que indivíduos portadores de má oclusão que não receberam tratamento ortodôntico apresentaram pré-molares e molares inferiores com maior angulação coronária em sentido mesial, independentemente da presença dos terceiros molares inferiores.

Salienta-se que a correção das angulações de pré-molares e molares durante o tratamento ortodôntico deve ser estabelecida como um dos requisitos para a correção da má oclusão, independentemente da presença dos terceiros molares.

Os valores angulares reduzidos correspondentes à angulação mesial de coroa acentuada, encontrados nos Grupos I e II, podem estar relacionados com outros fatores inerentes à má oclusão, como a curva de Spee acentuada e influência do componente anterior de forças, desempenhado pelos vetores funcionais e desgastes dentários. Dessa forma, as evidências apresentadas neste trabalho permitem inferir que os terceiros molares exercem pouca ou nenhuma influência no posicionamento angular mesiodistal dos caninos, pré-molares e molares inferiores.

Considerando as duas linhas de raciocínio que avaliam o desenvolvimento dos terceiros molares, os resultados dessa pesquisa corroboram com a mais recente $\mathrm{l}^{1,14,18,19,20,23,24,30}$, que defende o fato de que esses dentes não apresentam a capacidade de

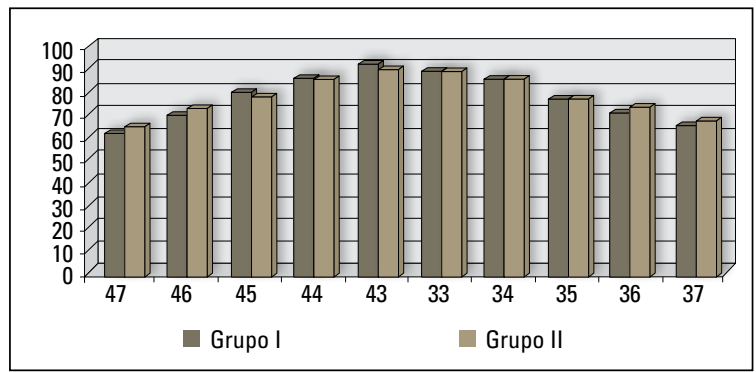

GRÁFICO 3 - Valores médios das angulações mesiodistais nos Grupos I e II. proporcionar todos os efeitos deletérios que a linha de raciocínio mais antiga apregoa ${ }^{3,15,16,29}$.

Assim, deve-se entender a etiologia dessas alterações como sendo multifatorial, uma vez que envolve a dinâmica do sistema estomatognático, como a componente anterior de forças ${ }^{30}$ e a presença de contatos proximais corretos ${ }^{16}$.

Como objetivo dessa pesquisa, foram comparados os valores do padrão médio normal das angulações mesiodistais de caninos, pré-molares e molares inferiores com os valores dessas angulações em indivíduos que apresentavam (Grupo I) ou não (Grupo II) os terceiros molares inferiores e, ainda, realizou-se a comparação dos valores destes dois grupos entre si. A semelhança dos valores entre os grupos e a diferença desses valores em relação ao padrão de normalidade (Gráf. 4) reiteram as afirmações anteriores.

Considerando a semelhança entre as angulações mesiodistais de caninos, pré-molares e molares inferiores, de indivíduos com e sem os terceiros molares inferiores, os resultados desse estudo sugerem que o profissional não deve se preocupar com a presença desses dentes, pois eles não constituem um fator capaz de alterá-las.

Cabe salientar que indivíduos com más oclusões de Classe I e Classe II não exibiram angulações de pré-molares e molares semelhantes àqueles com oclusão normal ${ }^{28}$. Esses dentes expuseram valores menores, ou seja, exibiram coroas mais anguladas em sentido mesial, quando comparados com o padrão de normalidade.

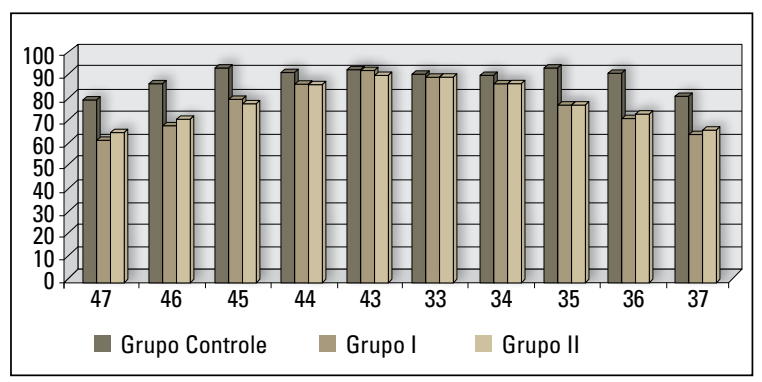

GRÁFICO 4 - Valores médios das angulações mesiodistais nos Grupos Controle, I e II. 
Os caninos, por sua vez, demonstraram não sofrer influência da má oclusão e dos terceiros molares. Dessa forma, devem ter suas angulações mesiodistais avaliadas pelo clínico, que provavelmente não as alterará, pois, conforme o presente estudo, apresentam seus valores médios semelhantes ao padrão de normalidade.

\section{CONCLUSÃO}

Os Grupos I e II, com e sem a presença dos terceiros molares inferiores, compostos por indivíduos que nunca haviam recebido tratamento ortodôntico e apresentavam má oclusão, quando comparados com o Grupo Controle de oclusão normal, exibiram:

- Pré-molares e molares inferiores mais angulados mesiodistalmente.
- Caninos inferiores com angulações mesiodistais semelhantes.

Os dois grupos avaliados apresentaram valores das angulações mesiodistais de caninos, pré-molares e molares inferiores semelhantes, de modo que:

- A presença dos terceiros molares não exerceu influência sobre essas angulações dentárias.

- A maior angulação mesiodistal nos pré-molares e molares inferiores de ambos os grupos sugere que essa é uma característica relacionada com os fatores inerentes à má oclusão e muito pouco envolvida com os terceiros molares.

\title{
Panoramic evaluation of the mesiodistal angulations of canine teeth, premolar and inferior molars with and without the presence of the third molars
}

\begin{abstract}
Aim: To compare the normal mean values of the mesiodistal axial angulation, proposed by Ursi in 1989, with the mesiodistal axial angulation of canine teeth, premolar and inferior molars in individuals with and without the presence of the third inferior molars and ages between 18 and 25 years. Besides, the values of the mesiodistal axial angulation of these teeth were compared in these two situations. Methods: Forty panoramic x-rays were used from individuals of both genders that didn't receive orthodontic treatment, divided in two groups: Group I, constituted by 20 x-rays that didn't present the third inferior molars, and Group II, formed by $20 x$-rays with the presence of the third inferior molars. Results and Conclusions: The results analysis and the statistical analysis allowed to conclude that both Groups exhibited inferior premolar and molars more angled in mesial direction when compared to the normal occlusion. On the other hand, the mesiodistal axial angulation of inferior canine teeth was similar to the presented in cases of normal occlusion. The two groups, when compared amongst themselves, exhibited similar angular values of the canine teeth, premolar and inferior molars, so that the presence of the third molars didn't exercise influence on these dental angulations.
\end{abstract}

Keywords: Third molar. Panoramic x-ray. Tooth angulation. Tooth movement. 


\section{REFERÊNCIAS}

1. ADES, A. G. et al. A long-term study of the relationship of third molars to changes in the mandibular dental arch. Am. J. Orthod. Dentofacial Orthop., St. Louis, v. 97, no. 4, p. 323-335, Apr. 1990.

2. ANDREWS, L. F. The six keys to normal occlusion. Am. J. Orthod., St. Louis, v. 62, no. 3, p. 296-309, Sept. 1972.

3. BERGSTRÖM, K.; JENSEN, R. Responsibility of the third molar for secondary crowding. Dent. Abstr., Chicago, v. 6, no. 9, p. 544-545, Sept. 1961.

4. CAPELOZZA FILHO, L. et al. Angulação dentária após o tratamento ortodôntico pela técnica de Andrews e Edgewise: avaliação pela ortopantomografia. Ortodontia, São Paulo, v. 27, n. 2, p. 60-66, maio/ago. 1994

5. CAPELOZZA FILHO, L. et al. Individualização de braquetes na técnica de Straight wire: revisão de conceitos e sugestão de indicações para uso. R. Dental Press Ortodon. Ortop. Facial, Maringá, v. 4, n. 4, p. 87-106, jul./ago. 1999.

6. CUOGHI, O. A. et al. Labiolingual and mesiodistal positioning of maxillary permanent incisors during the eruption process. J. Clin. Pediatr. Dent., Birmingham, v. 25, no. 1, p. 13-21, 2000.

7. DEMIRJIAN, A.; GOLDSTEIN, H.; TANNER, J. M. A new system of dental age assessment. Hum. Biol., Detroit, v. 45, no. 2, p. 211-227, May 1973.

8. DEWEL, B. F. Clinical observations on the axial inclination of teeth. Am. J. Orthod., St. Louis, v. 35, no. 2, p. 98-105, Feb. 1949.

9. EDWARDS, J. G. The prevention of relapse in extraction cases. Am. J. Orthod., St. Louis, v. 60, no. 2, p. 128-144, Aug. 1971.

10. FERRARIO, V. F. et al. Three-dimensional inclination of the dental axes in healthy permanent dentitions: A cross-sectional study in a normal population. Angle Orthod., Appleton, v. 71, no. 4, p. 257-264, Aug. 2001.

11. GLICKMAN, I. Princípios de occlusion. In:__. Periodontia clínica. 4. ed. México, DF: Interamericana, 1974. cap. 52, p. 808-833.

12. HATASAKA, H. H. A radiographic study of roots in extraction sites. Angle Orthod., Appleton, v. 46, no. 1, p. 64-68, Jan. 1976.

13 HOLDAWAY, R. A. Bracket angulation as applied to the edgewise appliance. Angle Orthod., Appleton, v. 22, no. 4, p. 227-236, Oct. 1952

14. KAPLAN, R. G. Mandibular third molars and postretention crowding. Am. J. Orthod., St. Louis, v. 66, no. 4, p. 411-430 Oct. 1974.

15. LASKIN, D. M. Evaluation of the third molar problem. J. Am. Dent. Assoc., Chicago, v. 82, no. 4, p. 824-828, Apr. 1971.

16. LINDQVIST, B.; THILANDER, B. Extraction of third molars in cases of anticipated crowding in the lower jaw. Am. J. Orthod., St. Louis, v. 81, no. 2, p. 130-139, Feb. 1982.
17. PEDRIN, R. R. A.; PINZAN, A.: ALMEIDA, R. R. Estudo ortopantomográfico das inclinações axiais dos dentes anteriores, comparando pacientes tratados ortodonticamente e jovens com oclusão normal. R. Dental Press Ortodon. Ortop. Facial, Maringá, v. 6, n. 5, p. 31-47, set./out. 2001.

18. RICHARDSON, M. E. Lower molar crowding in the early permanent dentition. Angle Orthod., Appleton, v. 55, no. 1, p. 51-57, Jan. 1985.

19. RICHARDSON, M. E. The etiology of late lower arch crowding alternative to mesially directed forces: A review. Am. J. Orthod. Dentofacial Orthop., St. Louis, v. 105, no. 6, p. 592-597 June 1994.

20. RICHARDSON, M. E. The role of the third molar in the cause of late lower arch crowding: A review. Am. J. Orthod. Dentofacial Orthop., St. Louis, v. 95, no. 1, p. 79-83, Jan. 1989.

21. ROTH, R. H. Functional occlusion for the orthodontist: Part III. J. Clin. Orthod., Boulder, v. 15, no. 3, p. 174-198, Mar. 1981.

22. ROTH, R. H. The Straight-wire appliance 17 years later. J. Clin. Orthod., Boulder, v. 21, no. 9, p. 632-642, Sept. 1987.

23. SOUTHARD, T. E. Third molars and incisor crowding: When removal is unwarranted. J. Am. Dent. Assoc., Chicago, v. 123 no. 8, p. 75-79, Aug. 1992.

24. SOUTHARD, T. E.; SOUTHARD, K. A.; WEEDA, L. W. Mesial force from unerupted third molars. Am. J. Orthod. Dentofacial Orthop., St. Louis, v. 99, no. 3, p. 220-225, Mar. 1991.

25. STRANG, R. H. Factors associated with successful orthodontic treatment. Am. J. Orthod., St. Louis, v. 38, no. 10, p. 790-800, Oct. 1952.

26. TAVANO, O. et al. Determinação de linhas de referência para medições angulares em radiografias ortopantomográficas. Odontol. Mod., Rio de Janeiro, v. 16, n. 9, p. 22-25, set. 1989

27. TUVERSON, D. L. Anterior interocclusal relations. Part I. Am. J. Orthod., St. Louis, v. 78, no. 4, p. 361-370, Oct. 1980.

28. URSI, W. J. S. Avaliação das inclinações axiais mesio-distais dos dentes superiores e inferiores em uma amostra de oclusão normal, não tratada ortodonticamente, utilizando radiografias ortopantomográficas, obtidas em diferente aparelhos. 1989. $99 \mathrm{f}$. Dissertação (Mestrado)-Faculdade de Odontologia de Bauru, Universidade de São Paulo, Bauru, 1989.

29. VEGO, L. A longitudinal study of mandibular arch perimeter Angle Orthod., Appleton, v. 32, no. 3, p. 187-192, July 1962.

30. WEINSTEIN, S. Third molar implications in Orthodontics. J. Am. Dent. Assoc., Chicago, v. 82, no. 4, p. 819-823, Apr. 1971.
Endereço para correspondência

Rodrigo Castellazzi Sella

Rua Jonatas Serrano, 825 - Centro

CEP: 86.060-220 - Londrina/PR

E-mail: rodrigosella@hotmail.com 